\title{
Cultura Cultura
}

Revista de Histroria Teroria das ldeais $\quad$ Revista de História e Teoria das Ideias

Vol. 26 | 2009

O Tempo das Revistas

\section{Em torno dos periódicos femininos}

On women's periodicals

\section{Teresa Salvador}

\section{OpenEdition}

Journals

Edição electrónica

URL: http://journals.openedition.org/cultura/425

DOI: $10.4000 /$ cultura. 425

ISSN: 2183-2021

\section{Editora}

Centro de História da Cultura

\section{Edição impressa}

Data de publição: 1 Junho 2009

Paginação: 95-117

ISSN: 0870-4546

\section{Refêrencia eletrónica}

Teresa Salvador, «Em torno dos periódicos femininos », Cultura [Online], Vol. 26 | 2009, posto online no dia 16 setembro 2013, consultado a 19 abril 2019. URL : http://journals.openedition.org/cultura/425 ; DOI : $10.4000 /$ cultura.425 


\title{
Em torno dos periódicos femininos
}

\author{
Teresa Salvador
}

\section{Primeira questão: valorizar}

As revistas femininas ${ }^{1}$ não são o género menor de uma espécie. Para o reconhecer, basta atender à crítica situacional e às propostas reformistas de certos artigos, entre os quais os dedicados ao sufragismo, ao divórcio, à educação e à formação profissional $^{2}$, artigos de provocação e resistência, que mobilizaram o público para o debate de ideias e que constituem, no seu todo, um legado de posições em confronto, com múltiplas variações. As revistas femininas são, como quaisquer revistas, plataformas de fixação de ideias e, por conseguinte, suportes incontornáveis para a história das mentalidades e dinâmicas sociais, de modo que esta não se sistematiza inteiramente sem as incluir e tomar como fonte de estudo.

A constatação de tal condição de imprescindibilidade contrasta com a situação de geral desconsideração a que têm estado sujeitas. Esta situação foi confirmada e exposta por Vitorino Magalhães Godinho durante um seminário por ele orientado na Universidade Nova de Lisboa, em 1979, tendo então sugerido a inventariação dos periódicos femininos. Ivone Leal, que informa sobre o caso, acolheu a sugestão e procedeu ao arrolamento de periódicos ${ }^{3}$, resultando o livro Um Século de Periódicos Femininos: Arrolamento de periódicos entre 1807 e 1926. No livro colocam-se duas questões que de modo algum são despiciendas: uma, qual a datação a ter em conta para o fecho do arrolamento?; outra, qual o critério de selecção dos periódicos? Atenda-se a cada uma delas.

\footnotetext{
Universidade de Évora.

1 Ao usar-se o termo "revista" está-se a ceder, tão-só momentaneamente, à designação comum, que não é adequada nem sequer vantajosa, como se mostrará mais tarde.

2 As mais antigas temáticas substantivas são o direito eleitoral e a instrução. Para o primeiro caso, verifique-se a colaboração de Virginia Wood em A Voz Feminina. Jornal semanal, científico, literário e noticioso exclusivamente colaborado por senhoras: dedicado às ilustres senhoras [5 Jan. 1868-27 Jun. 1869]. Trata-se de uma mulher conhecedora do que se passava lá fora (cf. a série de artigos "O que se faz lá fora" que publicou em O Progresso [4 jul. 1869-26 Dez. 1869]).

3 O seminário foi dedicado ao século XIX português. Cf. Leal, Ivone, Um Século de Periódicos Femininos. Arrolamento de periódicos entre 1807 e 1926, Lisboa, CIDM, 1992, p. 10.
} 
O ano de 1807 corresponde naturalmente ao lançamento de Correio das Modas, considerado pela autora como "o primeiro periódico conhecido", ao passo que, fosse qual fosse a data a fixar no final do século XIX ou no início do século XX para o fecho do levantamento a efectuar, ela não deixaria de ser artificialmente imposta. Neste período não se registaram rupturas no paradigma editorial nacional ou acontecimentos políticos com impacte nas concepções e práticas editoriais. Assim, desobrigada de assumir datas, Ivone Leal resolveu lucidamente a questão com a indicação do ano de introdução da censura em Portugal - 1926 -, por sinalizar uma descontinuidade na liberdade de expressão. Esta delimitação temporal permitiu obter uma primeira periodização, tomada como referência para efeitos de organização e estudo. Quanto à questão do critério de selecção, a autora optou por excluir, sem ser demasiado segregadora, os periódicos que não se dedicavam expressamente às mulheres ou se limitavam à "publicação de figurinos, desenhos, moldes ou músicas"4. O recurso a tal critério visou criar um corpus autónomo mediante o reconhecimento da especificidade das matérias abordadas. Deste modo, coube a Ivone Leal demarcar um sector da imprensa periódica como campo de estudo, na continuidade da linha avançada por Clara Rocha ${ }^{5}$ para as revistas literárias do século XX e depois seguida por António Nóvoa e Justino Magalhães ${ }^{6}$ para a imprensa escolar dos séculos XIX e XX, entre outros de outras áreas do saber ${ }^{7}$.

O critério de selecção estabelecido por Ivone Leal afigura-se pertinente, não pela evidente perspicácia intrínseca nem pela notória capacidade resolutiva, antes por

4 Idem, p. 12. Correio das Modas, de 1807 [Lisboa], é tido pela autora como "o primeiro periódico conhecido" (Idem, p. 13). Em Espanha, o periódico mais antigo, tanto quanto se sabe, é La Pensadora Gaditana, publicado em Madrid e em Cádis ao longo do ano de 1768. Era assinado por Beatriz Cienfuegos, supostamente o pseudónimo de um frade (cf.Leston, Xosé V.F., A prensa de mulleres en Galicia (1841-1994), Lisboa, Edições Universitárias Lusófonas, 1996, p. 21). O periódico mais antigo em Inglaterra é The Female Spectator, de Elizabeth Haywood, fundado em 1744. Note-se que a influência da imprensa estrangeira na criação dos periódicos portugueses, na opção temática e na abordagem dos conteúdos está por estudar.

5 O livro em causa é: Rocha, Clara, Revistas Literárias do Século XX em Portugal, Lisboa, Imprensa Nacional-Casa da Moeda, 1985.

6 De António Nóvoa, indicam-se dois títulos: Nóvoa, António, A Imprensa de Educação e Ensino. Repertório analítico (séculos XIX-XX), Lisboa, Instituto de Inovação Educacional, 1993; Nóvoa, António, "A imprensa de educação e ensino: Concepção e organização do Repertório português", in Catani, Denice B. \& Bastos, Maria Helena C. (orgs.), Educação em Revista - A imprensa periódica e a história da educação, S. Paulo, Escrituras, 1997, pp. 11-31. De Justino Pereira de Magalhães, remete-se para o artigo: Magalhães, Justino, "A imprensa de educação e ensino, repertório analítico (séculos XIX-XX)", Educação, Sociedade e Culturas, 3, 1995, pp. 216-219.

7 Um exemplo: Nunes, Fátima, Imprensa Periódica Científica (1772-1852). As leituras de "sciencia agrícola" em Portugal, Lisboa, Estar, 2001. 
remeter para o problema da vulnerabilidade deste tipo de publicação, associando-o a dois preconceitos, precisamente a frivolidade e a futilidade. Um e outro configuram acusações recorrentes: frivolidade pelo tratamento escrupuloso dado a assuntos irrelevantes ou, pelo contrário, pelo tratamento indiferente dado a matérias importantes; futilidade pela falta de sentido dos discursos, o que ridicularizava ou conferia indignidade a quem os assinava. Daí impor-se tantas vezes o cuidado em obscurecer a revelação do nome, sendo frequente o uso, quase lúdico, de pseudónimos, anagramas, acrósticos ou conjuntos de iniciais, cuja eficácia dependia da resistência à decifração.

O problema da vulnerabilidade, decorrente do predomínio de ideologias sexistas enraizadas, transversalizadas e internalizadas, tanto afectava os artigos dedicados à moda, quanto os artigos de conteúdo político: os primeiros, por serem considerados próprios das mulheres ou conformes à sua natureza; os segundos, por lhes serem impróprios ou estarem desajustados do papel social convencionado, naturalmente politicofóbico. Tal mentalidade contribuiu para inferiorizar a imprensa feminina perante a imprensa em geral que ganhara, por razões várias, uma forte consciência do valor de si mesma. Todavia, nem sempre os ataques depreciativos vinham do exterior. Muitas vezes constituíam-se e assumiam-se no interior do núcleo editorial, independentemente de os responsáveis serem homens ou mulheres. llustrativo é o texto de apresentação de Vida Feminina. Revista semanal da mulher e para a mulher, supostamente escrito por uma das secretárias de redacção ${ }^{8}$, onde se esclarece o público leitor sobre a natureza da revista: espaço "onde a mulher se sente mulher e onde a futilidade feminina, que é afinal a Vida, é tratada com algum carinho e sem política nenhuma"'.

Ao contrário do que acima se possa ter feito supor, a inferiorização não era participada por todos e nem toda a imprensa feminina se apresentava acomodada à imagem idealizada do "belo sexo", compreendida entre o próprio e o impróprio. Também se apresentou extrovertida, combativa e decidida a permanecer no espaço informativo, equacionando os problemas da mulher e da sociedade, juntando a vida privada com a pública e harmonizando valores. Dois efémeros periódicos exemplificam a diversidade

8 As secretárias de redacção eram Albertina Paraíso e Virgínia Quaresma. Para o conhecimento da actividade feminista de uma e outra, consulte-se a seguinte obra: Castro, Z. O. de, Esteves, J., Dicionário no Feminino (Séculos XIX-XX), Lisboa, Livros Horizonte, 2005.

9 Cf. Vida Feminina. Revista Semanal da Mulher e para a Mulher, p. 1. Procedeu-se sempre à actualização ortográfica das citações, por não se ver qualquer vantagem na fiel transcrição do português da época. 
de posicionamentos, ambos publicados em Lisboa no ano de 1822: um, O Toucador. Periódico sem política dedicado às senhoras ${ }^{10}$, dirigido e redigido por Almeida Garrett e Luís Francisco Midosi; outro, Gazeta das Damas ${ }^{11}$, propriedade de Caetano António de Lemos e redigido principalmente por três colaboradoras anónimas.

$\mathrm{Na}$ Introdução de O Toucador, declara-se que ficam intencionalmente de fora "as tarefas de politicar e despoliticar"12. E os títulos dos artigos - "Bailes,, "Jogo", "Modas", "Namoro", "Passeios" e "Teatro" - confirmam a mundaneidade da folha garrettiana, motivada e regulada por uma ideologia conservadora e vaporosamente coquette. É notório e óbvio o distanciamento de Almeida Garrett em relação às intelectuais suas contemporâneas. Numa linha editorial diferente, a Gazeta das Damas revela uma intenção formativa, edificante e interventiva, declarando-se uma folha "com política" para instrução das "tão benévolas leitoras dos negócios políticos"13. A invocação da necessidade nacional de aproximação das mulheres à política, pelo menos na qualidade de observadoras e comentadoras, coexiste, no mesmo espaço, com o apelo ao cultivo da domesticidade angélica, como se fosse insignificante e invisível o desacerto das duas mundividências. De facto, se alguns artigos não fazem contenção no uso do tom crítico, irónico e exaltado, outros postulam um ideal de mulher do tipo "companheira doméstica". Cita-se exemplificativamente: "Dama de um espírito cultivado, e de um coração bem formado, e virtuoso. Eis aqui a companheira, e não a escrava de seu condigno Esposo: Ela satisfaz os seus desejos, e alivia-lhe igualmente as suas penas; recompensa-lhe os seus cuidados, e suaviza a sua sorte por efusões de ternura: a gravidade, a ino-

10 Trata-se do segundo periódico feminino publicado em Lisboa, de 22 de Fevereiro a 7 de Março de 1822. Era exclusivamente redigido por Almeida Garrett e Luís Francisco Midosi. Conhecem-se sete números (1-7), cada um com dezasseis páginas, de formato rectangular $(a=17,8 / \mathrm{I}=11,5)$, produzidos na tipografia Imprensa Liberal.

11 Considera-se ser o terceiro periódico feminino: semanário publicado em Lisboa, de 29 de Novembro a 6 de Dezembro de 1822. Conhecem-se três números (1-3), cada um com quatro páginas, de formato rectangular ( $a=25,2 / \mathrm{I}=15,7)$, produzidos na tipografia J. F. M. de Campos e Régia Tip. Silvana. As três colaboradoras principais assinavam por: Uma Senhora Portuguesa; Semiramis; Uma Outra Anónima. As restantes escondiam a identidade.

12 Cf. s.a.,"Introdução," O Toucador, Lisboa, 1993, p. 27. Excluídas a política e as altas ciências, todo o interesse está nas notícias "da sociedade, do tom, da moda, etc." (Idem, p. 27).

${ }^{13}$ Cf. s.a.,"s.t.", Gazeta das Damas, 1 (Nov.) 1922, s. p. A mesma intencionalidade está subjacente no plano de trabalho que consistia "na sólida instrução de todas as classes do Belo-Sexo sobre os princípios da pura moral. No amor, em que pretendemos inflamar esta maioria da Nação pelas suas novas instituições, para que ela o inspire desde o berço à geração futura" (cf.ldem, s. p.). A instrução e a educação dominavam nos assuntos tratados, fosse para mobilizar os políticos ("As pensionistas do Estado"), fosse para reivindicar ("Educação") ou para reformar comportamentos ("Dever das mães"). 
cência e a modéstia mostrar-se-ão em seu rosto."14 A dificuldade em considerar, no momento da publicação, a possibilidade de existência de contradição ideológica entre o conteúdo dos artigos e o projecto editorial tipifica bem a imprensa feminina. Além do mais, admita-se, ser "boa filha, boa esposa e boa mãe" era um programa socialmente irrenunciável e politicamente estimável, por colaborar na promoção dos valores civilizacionais acantonados à volta da ideia de Progresso e vinculados ao reformismo liberal. Logo, o programa encaixava bem no modus vivendi familiar, ao mesmo tempo que seguia o espírito moderno, defensor da instrução e intervenção política das mulheres. Poucos foram os periódicos consistentes com a intransigência inerente à legitimidade da cidadania inclusiva e à aplicação de uma "ética mínima"15 baseada na justiça social, proporcionadora de bem-estar comum. A Gazeta das Damas não foi caso de excepção, não obstante a sua presença disruptiva na Lisboa de Oitocentos.

Para desconstruir preconceitos sobre as revistas femininas e apreciar entre elas as diferenças qualitativas, importa que à inventariação sucedam quer a selecção e análise de temáticas dominantes, quer a contextualização e comparação com outros discursos de época, nacionais e internacionais ${ }^{16}$. Ivone Leal deixou apenas subentendida esta orientação, posto que o objectivo imediato lhe condicionou o desenvolvimento.

14 Idem, s.p.

${ }^{15}$ A expressão "ética mínima" corresponde exactamente ao título de um livro de Adela Cortina [Ética Mínima. Introducción a la filosofía práctica, Madrid, Tecnos, 1986] e designa o referencial de exigência ética que garante o ideal da dignidade humana como absolutamente valioso e fim incondicionado.

${ }^{16}$ No livro de Xosé V. F. Leston, A prensa de mulleres en Galicia (1841-1994), encontra-se a seguinte observação à imprensa de mulheres em Portugal:"Malia a cantidade total de publicacións, case comparable a de España, debemos salientar que practicamente ningunha destas revistas pon en cuestión o modelo dominante acerca do papel social da muller. Neste aspecto esta prensa está mais próxima de galega que de española" (p. 58).

Não cabe neste trabalho, de abordagem incoativa e circunscrita a Portugal, a remissão para situações internacionais. Mas foi proveitosa a leitura do livro de Alison Adburgham (Women in Print. Writing Women and Women's Magazines from the Restoration to the Accession of Queen Victoria, London, Allen \& Unwin, 1972) e de Laurel Brake (Subjugated Knowledges, Journalism, Gender and Literature in the Nineteenth Century, London, Macmillan, 1994), onde merecem destaque quer a análise feita às revistas de mulheres publicadas entre 1880 e 1890, quer os debates da imprensa, quer a relação estabelecida entre mulheres escritoras e jornalistas. Pela razão supra-indicada, resistiu-se à tentação de sumariar o caso brasileiro exposto por Kátia de Carvalho ("As imagens femininas no Rio de Janeiro, anos 20:Um sistema de informação cultural", Ciência de Informação, vol. 20, 1, 1995), disponível na net, e Nelly Novaes Coelho ("A emancipação da mulher e a imprensa feminina.Século XIX-século X",Cosmo on line,1/12/2001). Registe-se a impossibilidade de consultar a dissertação de Maria Fernanda Baptista Bicalho, também brasileira (Bicalho, Maria Fernanda Baptista, O Belo Sexo: A imprensa, identidade feminina no Rio de Janeiro em fins do século XIX e inícios do século XX, Rio de Janeiro, Museu Nacional, 1988, 268 pp. [Dissertação]). Note-se que, apesar de não ter sido consultada, considerou-se que omitir a sua referência invisibilizava injustamente a obra. 
A investigação nesta linha foi assegurada por Ana Maria Costa Lopes, subordinando-a ao tema"a imagem da mulher" e limitando-a ao século XIX.Trata-se de um período significativo pelos antagonismos e contradições que modelavam e organizavam a vida das mulheres: por um lado, uma compulsiva fixação no círculo doméstico por contaminação de ideais do Romantismo sofisticado, do naturalismo exagerado e de certo modelo burguês emergente; por outro, uma ostensiva vontade de auto-afirmação pública e de denúncia da desigualdade cívica. Os periódicos, de grande popularidade e variedade em Oitocentos, contaminados por esses antagonismos e contradições, constituem uma fonte para a recuperação de imagens da mulher: reivindicativas ou subordinadas; frívolas e fúteis ou reflexivas e activas; instrumentalizadas ou desprezadas. Da investigação de Ana Maria Costa Lopes resultou o livro Imagens da Mulher na Imprensa Feminina de Oitocentos. Percursos de modernidade ${ }^{17}$, imprescindível leitura para compreender a configuração de estereótipos e correlacionar essas interpretações tópicas com as mundividências da época.

Ivone Leal e Ana Costa Lopes ${ }^{18}$ comprovaram que os periódicos femininos não são um género menor, quer como produto de imprensa, quer como fonte de investigação. Existe substância de pesquisa resultante dos posicionamentos pluralistas e críticos tomados com a participação nos debates da época.

\section{Segunda questão: classificar}

A leitura dos livros das duas autoras e a consulta de alguns periódicos femininos colocaram uma questão de ordem prática: no conjunto dos periódicos, como diferenciar revistas e jornais? A questão surge quando Ana Maria Costa Lopes refere, sem qualquer explicação, A Voz Feminina, O Progresso e A llustração Feminina como revis-

17 Cf. Lopes, Ana Maria Costa, Imagens da Mulher na Imprensa Feminina de Oitocentos. Percursos de modernidade, Lisboa, Quimera Editores, 2005.

18 Não são as únicas detentoras de elementos comprovativos, mas para o presente estudo elas são as autoras mais adequadas para o estudo do feminismo português. Em função deste critério, e sem diminuir o mérito de ninguém, não se tomou em consideração a dissertação de licenciatura de Rosemarie Wank-Nolasco Lamas, intitulada O Feminismo Português através da Leitura de Alma Feminina e de Portugal Feminino [Lisboa, Universidade Católica de Lisboa, 1993]. Também se não considerou o livro A Mulher em Textos e Contextos. Um recenseamento bibliográfico tematicamente indexado sobre publicações periódicas portuguesas (1974-1988), de Luís Esteves de Melo Campos [Lisboa, Comissão da Condição Feminina, 1989], pela mesma razão. A justificação serve ainda para o artigo de Liliana da Silva Araújo Simões, “A publicidade nas revistas femininas" [Boletim da Comissão da Condição Feminina, Ano X, n. ${ }^{\circ}$ 3-4 (Jul./Dez.) 1981, Lisboa, CCF, pp. 107-112]. 
tas ${ }^{19}$. Ora, as duas primeiras apresentam-se no subtítulo como jornais: A Voz Feminina. Jornal semanal, científico, literário e noticioso exclusivamente colaborado por senhoras: dedicado a ilustração das senhoras ${ }^{20} ;$ O Progresso. Jornal semanal político, literário e noticioso ${ }^{21}$. $O$ terceiro periódico assume-se apenas como semanário: $A$ llustração Feminina. Semanário d'instrução e recreio dedicado ao sexo feminino e redigido por várias senhoras e cavalheiros ${ }^{22}$. Da consulta de sessenta e uma publicações do século XIX (ver Anexo: Lista de periódicos femininos), verificaram-se duas situações: grande variabilidade na designação subtitulada, desde jornal, revista, semanário, periódico, publicação e incluindo folha; omissão da referência à categoria. A designação "revista" apenas se regista em Jornal das Damas. Revista de literatura e moda, de 1865-1879, A Mulher. Revista de família, de 1883-1885, e em A Jóia. Revista quinzenal literária, de 1887. O primeiro caso é deveras curioso por se reconhecer com dupla identidade, mas, comparando os três entre si e estes com os restantes periódicos de tipo jornal, não se detectam traços distintivos específicos e identificadores suficientes para extrair critérios de decisão.

O jornalista Silva Pereira, que em 1883 analisou vários periódicos femininos em cinco artigos publicados na revista $A$ Mulher, classificou-os a todos como jornal. Afirma: "Entre os jornais portugueses que em diversas épocas têm sido dedicados e oferecidos à mulher encontram-se alguns que tiveram vida efémera, outros que passaram por não poucas modificações e vicissitudes sem contudo se lhes alterar a índole, outros finalmente que foram bafejados pelas auras da estima pública, dando-se perfeitamente no santuário da família, sendo os enlevos da mamã e lidos com

19 Cf. Lopes, Ana Maria Costa, Imagens da Mulher na Imprensa Feminina de Oitocentos. Percursos de modernidade, Lisboa, Quimera Editores, 2005, p. 361.

${ }^{20}$ A Voz Feminina. Jornal semanal, científico, literário e noticioso exclusivamente colaborado por senhoras: dedicado a ilustração das senhoras foi publicado entre 5 de Janeiro de 1868 e 27 de Junho de 1869. Conhecem-se 76 números (1-50: 1868;51-76:1869), cada um com quatro páginas, de formato rectangular $(a=42,5 ; \mid=31,5)$, de periodicidade semanal e produzido na tipografia Voz Feminina, Tip. Luso-Britânica. A Redacção era constituída por Francisca Martins Wood, Guilherme Wood, Guiomar Torrezão e Pinho Almeida.

21 O Progresso. Jornal semanal político, literário e noticioso, continuação de $A$ Voz Feminina. Foi publicado entre 4 de Julho de 1869 e 26 de Dezembro de 1869. Conhecem-se 25 números, cada um com quatro páginas, de formato rectangular $(a=43 ; \mid=31)$, de periodicidade semanal e produzido na tipografia Luso-Britânica. A Redacção era constituída por Francisca Martins Wood e Guilherme Wood.

${ }^{22}$ A Ilustração Feminina. Semanário d'Instrução e recreio dedicado ao sexo feminino e redigido por várias senhoras e cavalheiros foi publicado entre 17 de Agosto de 1868 e 1 de Novembro de 1868. Conhecem-se doze números, cada um com quatro páginas, de formato rectangular $(a=43 ; \mathrm{I}=31)$, de periodicidade semanal e produzidos na Tipografia Lisbonense. 
avidez pelas filhas ${ }^{\prime \prime 23}$. Sendo Silva Pereira um estudioso do jornalismo, a uniformidade tipológica atribuída aos periódicos femininos corresponde ao modo usual de então os classificar - jornal -, tanto mais que já se havia estabelecido alguma distinção entre jornal e revista, segundo José Tengarrinha. $\mathrm{O}$ autor de História da Imprensa Periódica Portuguesa informa: “(...) foi o grande desenvolvimento da imprensa periodista em Portugal no $2 .^{\circ}$ quartel do século XIX que tornou possível e necessária a separação entre o jornal e a revista, não especialmente diferenciados pela periodicidade, mas pelas matérias que os constituíam e pela maneira de as desenvolver"24. Consultando os periódicos femininos, reconhece-se formato comum, paginação aproximada, arranjo gráfico similar e conteúdo afim, preenchido por notícias e artigos. A transferi-los da categoria "jornal" para a de "revista", ter-se-á de decidir, pelos critérios de Tengarrinha, se as matérias e o seu desenvolvimento, independentemente da novidade veiculada, da polémica suscitada ou mantida e da qualidade reflexiva incorporada, resultam ou não de processos de investigação com referenciais teóricos explícitos, quer sobre questões pertinentes, quer sobre problemas teóricos ou práticos. Esta grelha de malha apertada aplica-se bem para distinguir artigos académicos de artigos jornalísticos, ou seja, peças de construção discursiva reactiva, mais ou menos imediata, e com procedimentos argumentativos de impacte público moderado ou arrasador. Ora, o que se encontra nos periódicos femininos configura o artigo jornalístico e não o outro. A verdade, poder-se-á argumentar, é que nem todas as revistas são académicas, por conseguinte, os artigos também não, e Tengarrinha refere-se a eles. Nesse caso, mantendo a mesma linha de raciocínio, replicar-se-á que certos artigos jornalísticos são tão elaborados e ponderosos quanto os das revistas não-académicas. Logo, a diferença não é significativa, como Tengarrinha considerou. Ainda assim, como encontrar justificação para a adopção da designação "revista" para as três publicações mencionadas por Ana Costa Lopes?

Tome-se uma outra via para elucidação. Clara Rocha, que investigou a fundo as revistas literárias portuguesas do século XX, classificou-as em duas secções: uma que atende ao aspecto material e à periodicidade; outra que aprecia a matéria temática. Ao justificar a primeira secção, compara o jornal e a revista, considerando que aquele é mais efémero, tem maior frequência, dispensa capa, apresenta um formato maior e está obrigado à datação "porque se quer justamente em cima do acontecimento", seja

${ }^{23}$ Cf. Silva Pereira, "Jornais para as damas, Semanal das Musas, Jornal dos Amores ou as Calovriadas de Coimbra", A Mulher, (8) 1883, p. 63.

${ }^{24}$ Cf. José Tengarrinha, História da Imprensa Periódica Portuguesa, Lisboa, Portugália Editora, 1965, p. 134. 
ele qual for ${ }^{25}$. Tais características, válidas para as revistas em geral, confirmam, pelas razões acima aduzidas, que os periódicos femininos do século XIX correspondem maioritariamente ao tipo jornal.Todavia, no século XX o apuramento inclina-se a favor da revista. A simples existência de capa, a par de outros elementos menos ostensivos, já ajuda a decidir.

Na segunda secção, Clara Rocha reparte as revistas por grupos em função da matéria: de entretenimento e informação; culturais; marginais; políticas ou de opinião; artes e letras. A repartição aplica-se legitimamente aos jornais. Seguindo a classificação proposta, pode-se dizer que os jornais femininos do século XIX e inícios do século XX são sobretudo de convivência e informação utilitária (saúde, tarefas domésticas, educação, etc.), apresentando secções pequenas e variadas (notícias, rubricas de opinião, textos literários, moda, charadas), favorecendo a assimilação de dados com função prestativa no quotidiano doméstico e na criação de ambiente familiar, ou seja, promovendo a inserção da mulher no lar. A dimensão política ou cultural coexiste variavelmente em muitos.

A partir de 1926 e até 1974, preferiu-se a modelação do periódico em revista e boletim, neste caso se figurasse como órgão de uma associação com vínculo ao Estado Novo. O suplemento e a exclusividade da carga ideológica fizeram dos periódicos os mediadores entre a produção da informação consentida e o consumo da informação disponibilizada. Nada obsta a incluir alguns no grupo "política e opinião".

Em suma, para o século XIX é difícil argumentar a favor da troca de designação (jornal para revista) e nem se vê qualquer vantagem nisso. De modo algum os artigos ficam diminuídos em pregnância na afirmação da identidade pública das mulheres ou perdem pragmatismo na intenção de dar a conhecer abertamente tal identidade. Porque não designá-los por jornal, o termo que geralmente ostentam, ou simplesmente por periódico?

\section{Terceira questão: poderes e limites}

Quer o livro de Ana Costa Lopes, quer o de Ivone Leal induzem a considerar a importância da escrita jornalística na revelação da realidade que se é, se conhece e se constrói. Encontram-se muitos artigos em que a escrita se assume como instrumento de poder, permitindo dizer em público o que se quer dizer, e como instrumento do poder, obstaculizando dizer em público o que se gostaria de dizer ou dizendo tão-só o que o poder quer

${ }^{25}$ Cf. Clara Rocha, Revistas Literárias do Século XX em Portugal, Lisboa, Imprensa Nacional-Casa da Moeda, 1985 , p. 25. 
que seja dito. Ambas as autoras advertem para a multiplicidade de vozes femininas, umas afinadas, outras desafinadas com os vários discursos epocais, mas que no seu conjunto serviram o intuito, como refere Helena Konig, de "quebrar com os actos monológicos da razão masculina" (p. 209). Uma questão desponta aqui: como é que se foi legitimando a escrita do sujeito feminino, sexualmente diferenciado? Sem desprezar as determinantes históricas, sociais e económicas, sem dúvida que a escrita periódica se legitimou na medida em que o conceito de feminismo, um conceito de identidade, ganhou expressão e multiplicou as suas expressões. Em termos gerais, o feminismo corresponde a "la primera forma de identidad pública que las mujeres, ante una aguerrida minoría y, posteriormente, en grupos cada vez más extensos, se han otorgado desde el fin del siglo XVII"26. A identidade dá-se a conhecer pela voz e é mediante a escrita que as mulheres têm voz pessoal e pública. Ter voz significa conceber a vida agregada à coisa pública e, de certa maneira, bordejar o poder. Quatro ideias se configuram aqui em articulação:

- primeira, o feminismo é correlato do processo de autoconsciencialização da condição da mulher;

- segunda, a escrita, como registo da voz identitária, tem importante papel ilocutório cívico;

- terceira, a tipicidade do feminismo está na sua vinculação à "coisa pública", não obstante a variedade de manifestações e filiações;

- quarta, o repúdio do feminismo tem consequências emancipatórias negativas pela retracção política provocada.

Não é, pois, inconsequente optar-se por ser feminista, posição de vanguarda, ou por ser feminina, posicionamento mais conservador. Quando no século XIX e até meados do XX se repudiava o termo "feminista", numa compreensível demarcação da sua expressão violenta ${ }^{27}$ e num deliberado afastamento das correntes políticas que a ele se

${ }^{26}$ Trata-se de uma definição abrangente tomada para efeitos de trabalho, cuja referência filosófico-jurídica é a declaração de Olympe de Gouges, correctora da Declaração dos Direitos do Homem e do Cidadão, de 1789 (cf. Giulio de Martino e Marina Bruzzese, Las Filósofas. Las Mujeres Protagonistas en la Historia del Pensamiento, Valência, Ediciones Cátedra, 1996, p. 291). A não-univocidade do feminismo permite usar o termo no plural - feminismos. Assim se contempla um espectro de posicionamentos que vão do liberalismo moderado ao radicalismo defendido, por exemplo, por Betty Friedan (cf.Betty Friedan, The Feminine Mystique, Harmondsworth, Penguin, 1983).

27 Noticiosas eram as manifestações sufragistas promovidas pela inglesa Emmerline Pankhurst (1858-1938), fundadora da Women's Social and Political Union, em 1903, que terminavam, incontidamente, com violência, incêndios e destruições. 
associavam, e quando se tomava reactivamente a designação "feminina" ${ }^{\text {, }}$, a dimensão cívica perdia força reivindicativa no espaço público e provocava retracção política. Ora o esvaziamento da dimensão cívica gerava uma situação artificial e errática, dado que o horizonte ético onde pontuavam a igualdade entre os sexos e a emancipação jurídica e económica da mulher se desgarrava da acção reivindicativa cujo principal objectivo visava, em última instância, a participação e influência nas decisões governativas.

A dificuldade em optar por um ou outro conceito também se prende com o facto de o feminismo demorar a consolidar-se epistemologicamente, o que permitiria eliminar confusões conceptuais e vigiar eventuais contradições. Os periódicos do século XIX e de quase todo o século XX podem mostrar a relação entre a confusão dos posicionamentos e a inconsistência conceptual. Em A Assembleia Literária. Jornal d'instrução ${ }^{29}$, primeiro periódico fundado, pertencente e dirigido por uma mulher Antónia Pusich -, a infirmeza conceptual é evidente. Como escreve uma das colaboradoras em tom assertivo, trata-se de um "jornal redigido pelo espírito feminil" que investe na luta "pela nossa liberdade e pelos sagrados direitos que a sociedade nos tolhe" ${ }^{130}$. O suplemento de carga reivindicativa permite afirmar que o termo "feminil"é correlato de feminista. Porém, em Alma Feminina, boletim oficial do Conselho Nacional das Mulheres Portuguesas publicado entre 1917 e 1946 - "jornal de mulheres e feito por mulheres"-, declara-se no editorial que o feminismo "não quer roubar a mulher à família mas reivindica para ela direitos sociais mais extensos e complexos" ${ }^{\prime \prime 1}$.E, por não

28 O termo "feminina" tem uma conotação negativa por corresponder à internalização do ideal feminino, um constructo próprio do paradigma patriarcal que ideologicamente combina, tal como Simone de Beauvoir denunciou em O Segundo Sexo, a estrutura subjectiva da mulher e o comportamento social que dela é expectável. Ser feminina neste sentido corresponde à afirmação ou imposição da feminilidade. Feminina pode, ou não, ser solidário ou sinónimo de antifeminismo.

${ }^{29}$ A Assembleia Literária. Jornal d'instrução foi publicado em Lisboa entre 4 de Agosto de 1849 e 15 de Abril de 1851, inicialmente em regime semanal e depois quinzenal. Conhecem-se quarenta números (mais dezassete da 2. a série: 1951), cada um com oito páginas, de formato rectangular ( $a=25 / \mathrm{h}=18$ ), produzidos na Tipografia G. M. Martins, J. B. Morando, Tip. Gratidão, Imp. e Tip. de Alexandrina Amélia de Sales, Tipogafia de Silva, de Lisboa. Ivone Leal assinala o carácter inovador do jornal:“(...) na imprensa do século XIX a expressão'periódico feminino' queria dizer jornal destinado por homens a público feminino e contendo matérias que esses homens entendiam ser as que interessavam ou deviam interessar às mulheres. A partir da publicação de 'A Assembleia Literária' aquela expressão amplia-se e altera o seu significado, na exacta medida em que o conteúdo do jornal se torna diferente" (cf. Ivone Leal, Um Século de Periódicos Femininos. Arrolamento de periódicos entre 1807 e 1926, Lisboa, CIDM, 1992, p. 56).

${ }^{30}$ Cf. Antónia Luísa Pontes Cabral, 4 de Agosto de 1849, p. 1.

${ }^{31}$ Órgão do Conselho Nacional das Mulheres Portuguesas, Alma Feminina. Jornal de Instrução foi publicado em Lisboa entre Janeiro de 1917 e 15 de Maio de 1946, com regularidade mensal. 
querer ser exclusivamente feminista, integra actividades domésticas mais sofisticadas em secções como a moda e a ménagère, a literatura, a ciência, a vida social, a arte. Os motivos concretos, a vida real e os factos estão na base de uma doutrinação aparentemente neutra:"calmamente, sem intentos de revolução, sem impulsos e sem necessidade de nos encostarmos a qualquer doutrina político-religiosa"32. O programa editorial não vai além da razoabilidade moderada, sem determinação para recusar qualquer ordem de restrição interventiva e para defender a decisão pela própria vida.

Notável na crítica à homogeneidade e ao simbolismo do paradigma estruturante da humanidade é $A$ Voz Feminina. $O$ título exprime a estratégia adoptada: dar voz às mulheres através da escrita e deste modo mantê-las presentes no espaço público. $A$ expectativa potenciada pela dimensão política é imensa. Vale a pena transcrever esta significativa passagem:"Porque não poderão as senhoras escrever tão bem ou tão mal como os homens? Estamos a meados do século XIX e ainda não Ihes parece isso possível? As tolas e os tolos; as ignorantes e os ignorantes ou não escrevem ou escrevendo descrevem-se; ambos dizem tolices, ambos ostentam a sua falta de saber: as sensatas e os sensatos, as instruídas e os instruídos reproduzam-se como tais nos seus escritos. O sexo não influi nisso, mas sim o grau de talento com que nos achamos dotados e a cultura das nossas faculdades intelectuais. Acostumem-se, meus senhores e senhoras que duvidam, a crer que a instrução e as ideias que se adquirem estudando em diferentes países, as diferentes fases da família humana equiparam a mulher ao homem"33. $\mathrm{A}$ Voz Feminina, considerado por Ivone Leal como "o primeiro jornal feminista surgido na Europa" ${ }^{\prime \prime}$, apostou na constituição de ideais de cidadania inclusiva e tomou um sentido de eficácia e de serviço cívico exemplar no jornalismo nacional. O jornal criou imensa expectativa, potenciada pela dimensão política e novidade. Incomodou e foi extinto.

A falta de apoio, ou o apoio retirado ao jornal, prende-se com as diferentes concepções de ser feminista, quer dizer, de ter consciência da condição da mulher: uma, conservadora, interpreta o feminismo como uma manifestação com vista a reivindicar e assumir os direitos e deveres inerentes ao papel de esposa e mãe: outra, radical, interpreta-o como acção reivindicativa de direitos e deveres iguais entre os seres

32 Idem, p. 1.

${ }^{33}$ Cf. Francisca Wood, “Declaração”, A Voz Feminina, 35 (Set.) 1868, p. 1.

${ }^{34} \mathrm{Cf}$. Ivone Leal, Um Século de Periódicos Femininos. Arrolamento de periódicos entre 1807 e 1926, Lisboa, CIDM, 1992, p. 71. Francisca Wood também estava convencida disso mesmo: “Um jornal redactado por senhoras é hoje uma novidade na Europa, de cuja iniciativa deveríamo-nos, as portuguesas, ufanar-nos. Mas, segundo todas as aparências, não nos ufanamos" (cf. Francisca Wood, "Editorial", A Voz Feminina, n. ${ }^{\circ}$ 13,1868 , s.p.). 
humanos. O jornal de Francisca Wood provocou a reacção das mulheres vinculadas ao feminismo conservador, entre elas Maria Amália Vaz de Carvalho. Criticou-lhe o despropósito de ter voz pública, desafiante, esgrimista e invasora do espaço de influência e exercício do masculino poder político:"(...) o jornal, enfim, deve ser masculino, exclusivamente masculino, porque só os homens têm o espírito positivo que este género demanda" ${ }^{\prime 35}$. Quer uma quer outra, pela reacção e contra-reacção, foram legitimando a escrita do sujeito feminino como forma de sustento, e ambas sabiam que a escrita jornalística criava a oportunidade para a voz das mulheres se instalar publicamente. Maria Amália Vaz de Carvalho, que "rejeitou os ideais de emancipação igualitária das mulheres, atacou o divórcio e negou a legitimidade do outorgamento do direito de voto às mulheres" ${ }^{\prime 36}$, só poderia, por coerência, condenar; Francisca Wood só poderia fazer o que fez.

Os periódicos femininos foram (e são) mediadores das vozes das mulheres e dos modos de participação na vida pública ${ }^{37}$.

\section{Parágrafo conclusivo}

Que importa explorar e sistematizar temas, imagens e ideias disseminadas pela escrita jornalística da autoria de mulheres em periódicos femininos, é um dado adquirido. A abordagem que se realizou, embora preocupada em dilucidar questões prévias, afirma o potencial investigativo dos periódicos femininos, aliás confirmado pelas três dissertações académicas realizadas no espaço luso-brasileiro. Dois pontos a reforçar, para terminar: os periódicos têm legitimidade como objecto de estudo e deixam em aberto a possibilidade de uma leitura intertextual que faça emergir as diversas vontades de afirmação de um colectivo desdobrado em muitas gerações.

${ }^{35}$ Cf. Amália Vaz de Carvalho, "Correspondência”, A Voz Feminina, 25 (Set.) 1868, s.p. Resposta de Francisca Wood:"Se assim é, já não falta tudo, tendo uns dito que a redactora desta folha é um homem com bigodes retorcidos, outras que se quer fazer homem" (Idem, s.p.).

${ }^{36}$ Cf. Virgínia Dias, "Maria Amália Vaz de Carvalho", in Zília Osório de Castro e João Esteves, Dicionário no Feminino (Séculos XIX-XX), Lisboa, Livros Horizonte, 2005, p. 581.

37 Quarenta e seis anos mais tarde, escrevia-se em Alma Feminina, Boletim Oficial da Comissão Nacional das Mulheres Portuguesas:"On peut dire de la façon la plus absolue que le manque frappant d'équilibre moral, qu'on remarque dans les sociétés modernes, est la conséquence inévitable de l'absence de l'action consciente de la femme. Et voilà, pourquoi le féminisme, ayant pour but d'élever et de libérer la plus grande partie du genre humain, s'impose efficacement à tous les esprits illustrés. L'isolement auquel la femme a été condamnée et son éloignement de la vie publique a constitué toujours, et constitue, encore, un fort embarras au progrès" (cf. Alma Feminina, Ano 1, n. ${ }^{\circ}$ 1, 1915, pp. 1-2). 


\section{Anexo}

A Imprensa Feminista (1807-1974)

Lista de periódicos inventariados

\begin{tabular}{|c|c|c|c|}
\hline N.o & Anos & Periódicos & Localidade \\
\hline 1 & 1807 & Correio das Modas & Lisboa \\
\hline 2 & 1822 & Gazeta das Damas & Lisboa \\
\hline 3 & 1822 & $\begin{array}{l}\text { OToucador } \\
\text { Jornal sem política destinado às senhoras portuguesas }\end{array}$ & Lisboa \\
\hline 4 & 1823 & $\begin{array}{l}\text { Diálogo de Duas Velhas } \\
\text { As mulheres que são da antiguidade ao modernismo falam } \\
\text { verdade }\end{array}$ & Lisboa \\
\hline 5 & 1823 & $\begin{array}{l}\text { Eugénia } \\
\text { Dedicado às damas }\end{array}$ & Lisboa \\
\hline 6 & 1823-1824 & $\begin{array}{l}\text { Periódico das Damas } \\
\text { Semanal }\end{array}$ & Lisboa \\
\hline 7 & $\begin{array}{c}1836 \\
1840-1843 \\
1844-1853\end{array}$ & L'Abeille & Lisboa \\
\hline 8 & 1836 & $\begin{array}{l}\text { Colecção de Novas Modinhas } \\
\text { Para honesto recreio das madamas e apaixonadas do } \\
\text { harmonioso canto }\end{array}$ & Lisboa \\
\hline 9 & 1836 & $\begin{array}{l}\text { Semanal das Musas } \\
\text { Poesias feitas ou coleccionadas por M. C. A. e Silva }\end{array}$ & Lisboa \\
\hline 10 & 1836 & Tardes de Verão ou o Divertimento das Damas & Lisboa \\
\hline 11 & $\begin{array}{l}1836-1846 \\
1849-1852\end{array}$ & $\begin{array}{l}\text { O Correio das Damas } \\
\text { Ed.de modas. Semanal }\end{array}$ & Lisboa \\
\hline 12 & 1837 & Jornal dos Amores ou as Calovriadas de Coimbra & Lisboa \\
\hline 13 & $\begin{array}{l}1838-1839 \\
1842\end{array}$ & $\begin{array}{l}\text { O Beija-Flor } \\
\text { Semanário de instrução dedicado ao belo sexo }\end{array}$ & Lisboa \\
\hline 14 & 1839 & $\begin{array}{l}\text { Recreio Teatral } \\
\text { Dedicado ao belo sexo }\end{array}$ & Lisboa \\
\hline
\end{tabular}




\begin{tabular}{|c|c|c|c|}
\hline 15 & 1839 & $\begin{array}{l}\text { O Romancista } \\
\text { Jornal de recreio. Dedicado em especial ao belo sexo }\end{array}$ & Lisboa \\
\hline 16 & 1839 & $\begin{array}{l}\text { Pax Julia } \\
\text { Dedicado à Comissão de Senhoras que promove o bazar em } \\
\text { benefício da Soc. Teat. Bejense. Número único }\end{array}$ & Beja \\
\hline 17 & 1840 & A Rosa Oferecida às Belas & Lisboa \\
\hline 18 & 1842 & $\begin{array}{l}\text { O Toucador das Damas } \\
\text { Hebdomário literário }\end{array}$ & Lisboa \\
\hline 19 & 1845 & $\begin{array}{l}\text { O Jardim das Damas } \\
\text { O Jornal do Tom }\end{array}$ & Lisboa \\
\hline 20 & 1849 & $\begin{array}{l}\text { OMundo às Avessas } \\
\text { Semanário do belo sexo }\end{array}$ & Lisboa \\
\hline 21 & $1849-1851$ & $\begin{array}{l}\text { A Assembleia Literária } \\
\text { Jornal d'instrução }\end{array}$ & Lisboa \\
\hline 22 & $1850-1851$ & $\begin{array}{l}\text { O Judeu Errante } \\
\text { Jornal de modas e de literatura amena dedicado às } \\
\text { senhoras; Jornal de modas dedicado às senhoras }\end{array}$ & Lisboa \\
\hline 23 & 1851 & $\begin{array}{l}\text { A Açucena } \\
\text { Jornal de modas e literatura }\end{array}$ & Lisboa \\
\hline 24 & 1851 & $\begin{array}{l}\text { A Quinzena } \\
\text { Literatura, modas e teatros }\end{array}$ & Lisboa \\
\hline 25 & $1852-1855$ & $\begin{array}{l}\text { A Beneficência } \\
\text { Jornal dedicado à Associação Consoladora dos Aflitos }\end{array}$ & Lisboa \\
\hline 26 & $1853-1862$ & $\begin{array}{l}\text { OMensageiro das Damas } \\
\text { Jornal de modas }\end{array}$ & Lisboa \\
\hline 27 & 1856 & $\begin{array}{l}\text { O Interessante } \\
\text { Jornal de segredos }\end{array}$ & Braga \\
\hline 28 & 1856 & $\begin{array}{l}\text { Almanaque das Damas para o Ano de } 1856 \text { (Bissexto). } \\
\text { Dedicado às assinantes do Mensageiro das Damas }\end{array}$ & Lisboa \\
\hline 29 & $1858-1859$ & $\begin{array}{l}\text { A Cruzada } \\
\text { Jornal religioso e literário }\end{array}$ & Lisboa \\
\hline 30 & $1858-1860$ & $\begin{array}{l}\text { Mundo Elegante } \\
\text { Periódico das modas, literatura, teatros, belas-artes, etc.* } \\
\text { *A 2. a série de Mundo Elegante intitula-se O Mundo Elegante, Vila } \\
\text { Nova, } 1960 .\end{array}$ & Porto \\
\hline
\end{tabular}




\begin{tabular}{|c|c|c|c|}
\hline 31 & 1860 & A Moda Portuguesa & Porto \\
\hline 32 & 1862 & Emancipação da Mulher & Porto \\
\hline 33 & $1862-1863$ & Hinos e Flores & Coimbra \\
\hline 34 & 1862 & $\begin{array}{l}\text { Mensageiro das Damas } \\
\text { Jornal de literatura e modas }\end{array}$ & Lisboa \\
\hline 35 & 1863 & $\begin{array}{l}\text { Recreio das Damas } \\
\text { Oferecido às damas portuguesas de toda a Índia }\end{array}$ & Nova Goa \\
\hline 36 & $1863-1865$ & $\begin{array}{l}\text { Boudoir } \\
\text { Crítica, teatros, música, modas, notícias, caricaturas }\end{array}$ & Lisboa \\
\hline 37 & 1865 & $\begin{array}{l}\text { A Esperança } \\
\text { Semanário de recreio literário dedicado às damas }\end{array}$ & Porto \\
\hline 38 & $1867-1879$ & $\begin{array}{l}\text { Jornal das Damas } \\
\text { Revista de leitura e modas }\end{array}$ & Lisboa \\
\hline 39 & 1867 & $\begin{array}{l}\text { Flor Literária } \\
\text { Periódico científico, instrutivo, literário e de modas }\end{array}$ & Lisboa \\
\hline 40 & 1868 & $\begin{array}{l}\text { A llustração Feminina } \\
\text { Semanário de instrução e recreio dedicado ao sexo feminino }\end{array}$ & Lisboa \\
\hline 41 & $1868-1869$ & $\begin{array}{l}\text { A Voz Feminina } \\
\text { Jornal seminal científico, literário e noticioso. } \\
\text { Exclusivamente colaborado por senhoras }\end{array}$ & Lisboa \\
\hline 42 & 1869 & $\begin{array}{l}\text { O Progresso } \\
\text { Jornal político, literário e noticioso }\end{array}$ & Lisboa \\
\hline 43 & $\begin{array}{l}1870-1890 \\
1928\end{array}$ & Almanaque das Senhoras & Lisboa \\
\hline 44 & 1875 & Bouquet Literário & Porto \\
\hline 45 & 1876 & $\begin{array}{l}\text { Teatro e Modas } \\
\text { Publicação hebdomadária }\end{array}$ & Porto \\
\hline 46 & $1876-1877$ & $\begin{array}{l}\text { A Borboleta } \\
\text { Hebdomadário dedicado às damas bracarenses }\end{array}$ & Braga \\
\hline 47 & 1877 & $\begin{array}{l}\text { Gazeta das Salas } \\
\text { Jornal para as damas }\end{array}$ & Lisboa \\
\hline 48 & 1877 & $\begin{array}{l}\text { Jornal das Senhoras } \\
\text { Publicação diária }\end{array}$ & Porto \\
\hline
\end{tabular}




\begin{tabular}{|c|c|c|c|}
\hline 49 & 1879 & $\begin{array}{l}\text { O Pirilampo } \\
\text { Folha quinzenal literária e filosófica, dedicada às damas } \\
\text { bracarenses }\end{array}$ & Braga \\
\hline 50 & 1882 & $\begin{array}{l}\text { As Damas Portuguesas } \\
\text { Jornal literário }\end{array}$ & Porto \\
\hline 51 & 1883 & $\begin{array}{l}\text { O Elegante } \\
\text { Jornal de modas para homens, senhoras e crianças. } \\
\text { Dedicado particularmente aos alfaiates e costureiras }\end{array}$ & Lisboa \\
\hline 52 & 1883 & OBouquet & Porto \\
\hline 53 & 1883 & $\begin{array}{l}\text { A Mulher } \\
\text { Jornal de modas }\end{array}$ & Funchal \\
\hline 54 & 1883-1885 & $\begin{array}{l}\text { A Mulher } \\
\text { Revista ilustrada da família }\end{array}$ & Lisboa \\
\hline 55 & 1884-1885 & $\begin{array}{l}\text { As Crianças } \\
\text { Jornal de educação dedicado às mães }\end{array}$ & Lisboa \\
\hline 56 & $1884-1886$ & Gazeta Musical & Lisboa \\
\hline 57 & 1885-1888 & Almanaque das Senhoras Portuenses & Porto \\
\hline 58 & 1885 & $\begin{array}{l}\text { O Cartão de Visita } \\
\text { Semanário das elegantes }\end{array}$ & Coimbra \\
\hline 59 & 1885 & $\begin{array}{l}\text { Beja-Creche } \\
\text { Número único. Publicado pela comissão da creche e } \\
\text { dedicado às senhoras que a têm coadjuvado }\end{array}$ & $\begin{array}{c}\text { Beja } \\
\left(2 .^{\text {a ed. }}\right. \\
\text { Coimbra })\end{array}$ \\
\hline 60 & 1886 & OBouquet & Porto \\
\hline 61 & 1886 & $\begin{array}{l}\text { A Mocidade } \\
\text { Semanário de instrução e de recreio dedicado às damas } \\
\text { portuguesas }\end{array}$ & Porto \\
\hline 62 & 1886 & $\begin{array}{l}\text { O Sinapsismo } \\
\text { Jornal em prosa e verso }\end{array}$ & $\begin{array}{c}\text { Ponta } \\
\text { Delgada }\end{array}$ \\
\hline 63 & 1886 & $\begin{array}{l}\text { A Pátria } \\
\text { Periódico destinado às costureiras }\end{array}$ & Porto \\
\hline 64 & $1886-1887$ & $\begin{array}{l}\text { Lisboa Elegante } \\
\text { Contos, versos, teatros e bailes }\end{array}$ & Lisboa \\
\hline 65 & 1887 & $\begin{array}{l}\text { A Arte } \\
\text { Semanário literário dedicado às damas reguenses }\end{array}$ & Régua \\
\hline
\end{tabular}




\begin{tabular}{|c|c|c|c|}
\hline 66 & 1887 & $\begin{array}{l}\text { O Bocage } \\
\text { Semanário literário, científico e noticioso }\end{array}$ & Lisboa \\
\hline 67 & 1887 & $\begin{array}{l}\text { O Cisne } \\
\text { Semanário literário, noticioso e charadístico dedicado às } \\
\text { damas lamacenses }\end{array}$ & Lamego \\
\hline 68 & 1887 & $\begin{array}{l}\text { A Corbeille } \\
\text { Semanário literário d'instrução e recreio, dedicado às damas } \\
\text { portuenses }\end{array}$ & Porto \\
\hline 69 & 1887 & $\begin{array}{l}\text { O Escalpelo } \\
\text { Semanário literário e de crítica imparcial }\end{array}$ & Lisboa \\
\hline 70 & 1887 & $\begin{array}{l}\text { A Grinalda } \\
\text { Semanário literário, científico, noticioso e charadístico. } \\
\text { Dedicado às Exmas. damas desta cidade }\end{array}$ & Elvas \\
\hline 71 & 1887 & $\begin{array}{l}\text { A Jóia } \\
\text { Revista quinzenal de literatura dedicado às damas } \\
\text { vimaranenses }\end{array}$ & Guimarães \\
\hline 72 & 1887 & $\begin{array}{l}\text { O Mundo Elegante } \\
\text { Mensageiro semanal de modas e bom tom. Dedicado às } \\
\text { senhoras portuguesas e brasileiras }\end{array}$ & Paris \\
\hline 73 & 1887 & $\begin{array}{l}\text { A Rosa } \\
\text { Publicação quinzenal literária. Dedicada às damas } \\
\text { portuguesas }\end{array}$ & Porto \\
\hline 74 & 1888 & $\begin{array}{l}\text { O Dedal } \\
\text { Quinzenário noticioso e literário dedicado às costureiras }\end{array}$ & Porto \\
\hline 75 & 1889 & $\begin{array}{l}\text { O Agulheiro } \\
\text { Destinado às costureiras }\end{array}$ & Porto \\
\hline 76 & 1889 & $\begin{array}{l}\text { O Alfinete } \\
\text { Semanário humorístico destinado às costureiras }\end{array}$ & Porto \\
\hline 77 & 1890 & $\begin{array}{l}\text { Gazeta das Salas } \\
\text { Periódico literário dedicado às damas portuguesas e } \\
\text { brasileiras }\end{array}$ & Lisboa \\
\hline 78 & 1890 & $\begin{array}{l}\text { A Pérola } \\
\text { Semanário literário destinado às Exmas. damas desta } \\
\text { cidade }\end{array}$ & Elvas \\
\hline 79 & 1890 & $\begin{array}{l}\text { A Religião da Mulher } \\
\text { Jornal noticioso e auxiliador do professorado }\end{array}$ & $\begin{array}{l}\text { Albergaria- } \\
\text {-a-Velha }\end{array}$ \\
\hline
\end{tabular}




\begin{tabular}{|c|c|c|c|}
\hline 80 & 1893 & $\begin{array}{l}\text { A Tesoura } \\
\text { Semanário humorístico. Órgão das costureiras }\end{array}$ & Porto \\
\hline 81 & 1893 & $\begin{array}{l}\text { OMundo Musical } \\
\text { Jorna das damas portuguesas e brasileiras. Anunciador da } \\
\text { moda }\end{array}$ & Lisboa \\
\hline 82 & 1894 & $\begin{array}{l}\text { O Boletim da Moda } \\
\text { Revista dos Armazéns Grandela }\end{array}$ & Lisboa \\
\hline 83 & 1894 & O Jornal das Damas & Porto \\
\hline 84 & 1894-1985 & $\begin{array}{l}\text { A Estação de Paris } \\
\text { Revista de modas, literatura, elegância e bom tom }\end{array}$ & Lisboa \\
\hline 85 & 1895 & $\begin{array}{l}\text { A Utilidade } \\
\text { Revista de interesse da economia doméstica }\end{array}$ & Lisboa \\
\hline 86 & 1896 & $\begin{array}{l}\text { A Crónica } \\
\text { Suplemento à Estação de Paris }\end{array}$ & Lisboa \\
\hline 87 & 1896 & $\begin{array}{l}\text { Jornal das Senhoras } \\
\text { Semanário ilustrado colaborado por damas }\end{array}$ & Lisboa \\
\hline 88 & 1897 & A Moda Elegante & $\begin{array}{l}\text { Paris e } \\
\text { Lisboa }\end{array}$ \\
\hline 89 & 1899-1900 & Ave Azul & Viseu \\
\hline 90 & 1902 & $\begin{array}{l}\text { Jornal das Senhoras } \\
\text { Publicação trissemanal ilustrada }\end{array}$ & Lisboa \\
\hline 91 & 1902-1904 & $\begin{array}{l}\text { A Sociedade Futura } \\
\text { Publicação quinzenal de literatura, ciência e arte }\end{array}$ & Lisboa \\
\hline 92 & 1904 & Os Serões das Senhoras & - \\
\hline 93 & 1904-1905 & $\begin{array}{l}\text { Jornal das Senhoras } \\
\text { Retratos, biografias, romances, letras e contos, teatro e } \\
\text { salões. modas, contos e charadas }\end{array}$ & Lisboa \\
\hline 94 & 1906-1910 & $\begin{array}{l}\text { Jornal da Mulher } \\
\text { (Secção de OMundo) }\end{array}$ & Lisboa \\
\hline 95 & 1907-1908 & Alma Feminina & Lisboa \\
\hline 96 & 1909-1911 & $\begin{array}{l}\text { A Mulher e a Criança } \\
\text { Revista quinzenal ilustrada }\end{array}$ & Lisboa \\
\hline 97 & 1910 & $\begin{array}{l}\text { A Violeta } \\
\text { Dedicada às senhoras e meninas de Castelo de Vide }\end{array}$ & $\begin{array}{l}\text { Castelo } \\
\text { de Vide }\end{array}$ \\
\hline
\end{tabular}




\begin{tabular}{|c|c|c|c|}
\hline 98 & 1910 & $\begin{array}{l}\text { O Jornal da Mulher } \\
\text { Revista quinzenal ilustrada }\end{array}$ & Lisboa \\
\hline 99 & 1910 & Mosaico Feminino & Coimbra \\
\hline 100 & 1911-1918 & $\begin{array}{l}\text { A Madrugada } \\
\text { Propriedade da Liga Republicana das Mulheres Portuguesas }\end{array}$ & Lisboa \\
\hline 101 & 1912 & $\begin{array}{l}\text { Em Homenagem a Ana Pereira } \\
\text { Número único }\end{array}$ & Lisboa \\
\hline 102 & 1912 & $\begin{array}{l}\text { A Mulher Livre } \\
\text { Centro da Mocidade Republicana Intransigente } \\
\text { Número único }\end{array}$ & Braga \\
\hline 103 & 1912 & $\begin{array}{l}\text { A Mulher Livre } \\
\text { Revista mensal educativa. Órgão da Associação de } \\
\text { Propaganda Feminista }\end{array}$ & Lisboa \\
\hline 104 & $1912-1913$ & $\begin{array}{l}\text { A Mulher Portuguesa. } \\
\text { Revista mensal educativa } \\
\text { Associação de Propaganda Feminista }\end{array}$ & Lisboa \\
\hline 105 & 1913 & $\begin{array}{l}\text { Educação Feminista } \\
\text { Quinzenário literário, científico e artístico }\end{array}$ & Lisboa \\
\hline 106 & 1914 & A Guerra & Lisboa \\
\hline 107 & $\begin{array}{l}1914 \\
1915\end{array}$ & $\begin{array}{l}\text { Parisiana } \\
\text { Revista llustrada de elite e literatura, arte e música }\end{array}$ & Porto \\
\hline 108 & 1914-1917 & $\begin{array}{l}\text { Boletim Oficial do Conselho Nacional das Mulheres } \\
\text { Portuguesas }\end{array}$ & Lisboa \\
\hline 109 & 1915 & A Vida Elegante & - \\
\hline 110 & 1915-1918 & $\begin{array}{l}\text { A Semeadora } \\
\text { Associação de Propaganda Feminista }\end{array}$ & Lisboa \\
\hline 111 & 1917 & $\begin{array}{l}\text { Moda Elegante } \\
\text { Enciclopédia da mulher }\end{array}$ & Lisboa \\
\hline 112 & 1917-1946 & $\begin{array}{l}\text { Alma Feminina } \\
\text { Boletim oficial do Conselho Nacional das Mulheres } \\
\text { Portuguesas }\end{array}$ & Lisboa \\
\hline 113 & 1921 & $\begin{array}{l}\text { A Mulher Médica na Família } \\
\text { Revista quinzenal ilustrada }\end{array}$ & Lisboa \\
\hline 114 & 1922 & $\begin{array}{l}\text { A Rainha da Moda } \\
\text { Figurino Português da Grande Moda de Paris }\end{array}$ & - \\
\hline
\end{tabular}




\begin{tabular}{|c|c|c|c|}
\hline 115 & 1925 & $\begin{array}{l}\text { Estrela } \\
\text { Órgão do Comité Nacional das UCMF }\end{array}$ & Porto \\
\hline 116 & 1925 & $\begin{array}{l}\text { Eva Magazine } \\
\text { Jornal da mulher e do lar }\end{array}$ & Lisboa \\
\hline 117 & 1925 & $\begin{array}{l}\text { A Moda } \\
\text { Jornal para senhoras }\end{array}$ & Lisboa \\
\hline 118 & 1925 & $\begin{array}{l}\text { Vida Feminina } \\
\text { Revista mensal da mulher para a mulher }\end{array}$ & Lisboa \\
\hline 119 & 1925-1927 & $\begin{array}{l}\text { Mulheres do Norte } \\
\text { Mensário de arte e literatura }\end{array}$ & Porto \\
\hline 120 & 1926 & $\begin{array}{l}\text { Femina } \\
\text { Literatura, arte e moda }\end{array}$ & Lisboa \\
\hline 121 & 1930 & Portugal Feminino & Lisboa \\
\hline 122 & 1931 & $\begin{array}{l}\text { Fémina } \\
\text { Arte e moda }\end{array}$ & Lisboa \\
\hline 123 & 1932 & $\begin{array}{l}\text { Feminismo } \\
\text { Órgão do Instituto de Higiene Física }\end{array}$ & Lisboa \\
\hline 124 & 1946-1947 & $\begin{array}{l}\text { A Mulher } \\
\text { Órgão do Conselho Nacional das Mulheres Portuguesas }\end{array}$ & Lisboa \\
\hline 125 & $\begin{array}{l}1942-1958 \\
1964\end{array}$ & $\begin{array}{l}\text { Os Nossos Filhos } \\
\text { Mensário de puericultura, enfermagem, psicologia, } \\
\text { educação, vida escolar, literatura, moda infantil, etc. }\end{array}$ & Lisboa \\
\hline 126 & 1944-1952 & Boletim da Associação Feminina Portuguesa para a Paz & Lisboa \\
\hline 137 & 1955 & $\begin{array}{l}\text { Cinderela. } \\
\text { Revista para mulheres }\end{array}$ & Lisboa \\
\hline 128 & 1956 & Crónica Feminina & Lisboa \\
\hline 129 & 1957 & Ela & Lisboa \\
\hline 130 & 1957 & Jornal Feminino & Porto \\
\hline 131 & 1959 & Almanaque de Crónica Feminina & Lisboa \\
\hline
\end{tabular}




\section{Observação}

A lista apresentada resulta da consulta de dois livros (Ivone Leal, Um Século de Periódicos Femininos. Arrolamento de periódicos entre 1807 e 1926, e Ana Maria Costa Lopes, Imagens da Mulher na Imprensa Feminina de Oitocentos. Percursos de modernidade), de dois dicionários (Dicionário no Feminino. Séculos XIX-XX e Dicionário da Imprensa Periódica Literária Portuguesa do Século XX.1941-1974) ${ }^{38}$ e ainda de dois livros de Silva Pereira (Os Jornais Portugueses e Jornalismo Português) ${ }^{39}$.

Da lista, excluíram-se Moda llustrada (Lisboa, 1875), A Moda llustrada (Lisboa, 1879) e A Moda (Porto, 1882), pois esgotam-se nesse campo temático.

Incluíram-se periódicos escritos por homens, por homens e mulheres e só por mulheres, de vários tipos e destinados a vários sectores, como, por exemplo, as costureiras, o único grupo profissional com reconhecimento (cf. A Pátria, O Dedal, O Agulheiro, $O$ Alfinete, A Tesoura).

Excluiu-se O Idealista, quinzenário dirigido e editado por Áurea Paes Falcão ( $A$ Andorinha), publicado em Odemira entre 15 de Março de 1931 e 19 de Julho desse ano, num total de dez números. A razão é uma só: dirige-se ao público em geral com os objectivos de "Sobretudo Educar", de evitar questões políticas, religiosas e sobre a igualdade, e de regionalizar ("Do nosso programa consta também um pouco de regionalismo" $)^{40}$.

Incluíram-se gazetas e almanaques, seguindo o critério de Silva Pereira.

No Relatório das Publicações Periódicas Portuguesas de 1964 (Lisboa, Biblioteca Nacional) e no Suplemento referente ao ano de 1962, encontrou-se na Secção Economia Doméstica (pp. 237-238) uma lista de periódicos dirigidos ao concreto das mulheres esposas e mães, na linha, por exemplo, de $A$ Mulher (1883), As Crianças (1884) e $A$ Utilidade (1895). Dela não se consideraram: Modas e Bordados. Vida Feminina (Lisboa, 1912); O Enxoval da Noiva (Lisboa, 1951); A Mulher no Lar (Lisboa, 1957); Bordados à Máquina (Lisboa, 1958); O Bastidor e... a Máquina (Lisboa, 1959); Mãos de Fadas. Revista mensal de lavores (Lisboa, 1961). Trata-se de revistas técnicas ou limitadas a um só campo.

${ }^{38}$ Cf. Pires, Daniel, Dicionário da Imprensa Periódica Literária Portuguesa do Século XX (1941-1974), 2 vols., Lisboa, Grifo Limitada, 1999.

${ }^{39}$ Cf. Silva Pereira, Jornalismo Português, Lisboa, Typ. Tavares, 1895; Os Jornais Portugueses, Lisboa, Imp. Libanio da Silva, 1898.

40 Vale a pena transcrever a justificação dada por Áurea Paes Falcão no editorial do primeiro número do jornal:"Nunca sonhámos ser outra coisa que não fosse esposa e mãe, mas foi justamente esse mister sublime superior a todos os misteres que Deus, nos seus insondáveis propósitos, não quis conceder-nos...." 
Após alguma hesitação, decidiu-se excluir Mãos Dadas, Fagulha e Menina e Moça, da Mocidade Portuguesa Feminina, precisamente por se dirigirem à juventude. A incluí-las, deveriam ter-se em consideração outras que surgiram, por exemplo, no âmbito dos Centros Escolares e de certas escolas, como as de enfermagem.

Excluíram-se os periódicos publicados depois do 25 de Abril de 1974, por requererem uma pesquisa, de momento impossível de realizar. Tal significou não considerar Faces de Eva. Estudos sobre a mulher, revista académica, nem Ex æquo, revista da Associação Portuguesa de Estudos sobre as Mulheres, ambas lançadas em 1999 e ambas referenciadoras.

A lista, que não se considera estar completa, pois é expectável a descoberta de outros periódicos, optou por dar prioridade ao ano de publicação, seguido do nome e subtítulo do periódico e do local de publicação. Deste modo, pretendia-se obter leituras passíveis de responder imediatamente às seguintes questões: Quantas revistas foram publicadas por ano, em cada século e no total dos dois séculos? Quais os periódicos que se assumiam como revista? Onde eram publicados? Sumariamente, verifica-se que, dos 131 títulos, 71 foram publicados em Lisboa, 25 no Porto, um simultaneamente em Lisboa e Paris, outro apenas em Paris e os restantes 32 pontuaram de norte a sul em localidades de distinta dimensão. Constata-se que em 1878 foram publicados nove periódicos em locais diversos, estando outros em publicação. Numa análise temática geral, os conteúdos integram-se mais ou menos nos mesmos campos: Higiene e medicina, Crítica e reivindicação, Vida social, Conhecimentos úteis, Receitas culinárias, Moda, Relatos históricos, Costumes, Curiosidades, Literatura, Charadismo e Anedotas. 